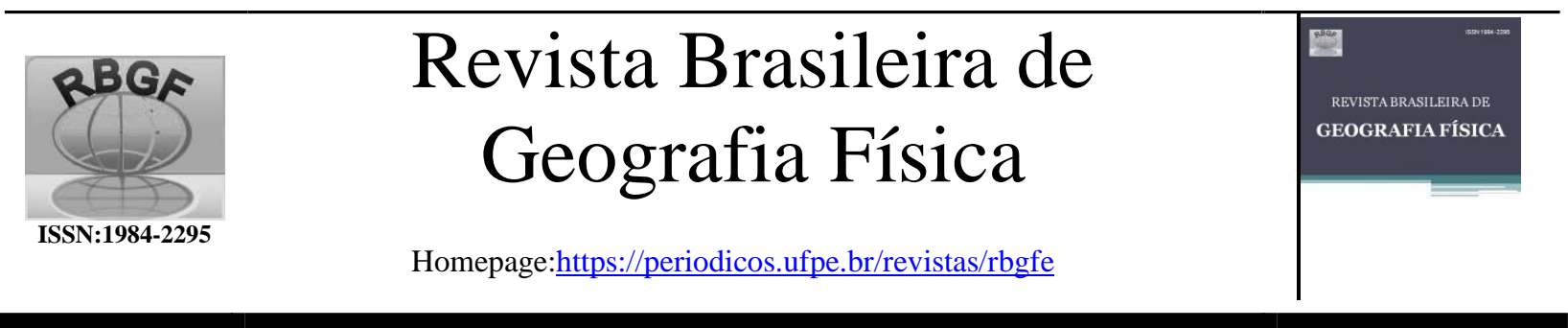

\title{
Análise da Evolução do uso e ocupação das terras no arrondissement de Arcahaie- Haiti (1987, 1997 E 2018)
}

\author{
Ralph Charles ${ }^{1}$, Regina Célia de Oliveira ${ }^{2}$, Ivonice Sena de Souza ${ }^{3}$
}

\begin{abstract}
${ }^{1}$ Dr. em Meteorologia Agrícola, Professora Assistente I, Unidade Acadêmica de Serra Talhada, Universidade Federal Rural de Pernambuco, Fazenda Saco, s/n, CEP 56900-000, Serra Talhada, Pernambuco. (87) 3929-3216. sanddrabastos@ yahoo.com.br (autor correspondente). ${ }^{2}$ Dr. Pesquisadora, Embrapa Semiárido, BR 428, Km 152, Zona Rural - Caixa Postal 23, CEP 56302-970, Petrolina, Pernambuco. (87) 3866-3600. magna_upa@ hotmail.com. ${ }^{3}$ Professor Titular, Departamento de Engenharia Agrícola, Unidade Federal de Viçosa, Av. P.H. Holfs, s/n, CEP 36570000, Viçosa, Minas Gerais. (31) 3899-1880. g.sediyama@ufv.br. ${ }^{4}$ Professor Dr. Adjunto III, Unidade Acadêmica de Serra Talhada, Universidade Federal Rural de Pernambuco, Fazenda Saco, s/n, CEP 56900-000, Serra Talhada, Pernambuco. (87) 3929-3208. thieres_freire@yahoo.com.br. Artigo recebido em 02/01/2021 e aceito em 14/09/2021
\end{abstract}

R E S U M O

Atualmente, utiliza-se os recursos da natureza de forma exploratória, sem a projeção dos impactos que essa atitude pode ocasionar, gerando problemas de caráter social e/ou ambiental, podendo apresentar seus efeitos rapidamente ou em grande escala de tempo. No Haiti, constata-se que a região possui incapacidade de enfrentar qualquer problema de caráter ambiental, essa situação está relacionada diretamente com as atividades antrópicas. Nesse sentido, a presente pesquisa teve como objetivo analisar a evolução temporal do uso e ocupação da terra do Arrondissement de Arcahaie, localizada a Oeste do Haiti. O Arrondissement é uma divisão administrativa do território haitiano que é composta por vários municípios. O método utilizado foi uma fotointerpretação sobre o recorte das Imagens Landsat 5 e Landsat 8, referente a área de estudo. Para o mapeamento foi utilizada a classificação supervisionada. As classes de uso e ocupação definidas foram: pastagem, cobertura vegetal, solo exposto, área cultivada, área urbana, mata natural. Os resultados mais significativos mostram mudanças na dinâmica de uso e ocupação da terra no Arrondissement de Arcahaie, durante 31 anos e consequentemente, podendo causar danos, muitas vezes, irreversíveis ao meio ambiente e comprometer a qualidade de vida da população.

Palavras-chave: Impactos Ambientais. Recursos Naturais. Arrondissement de Arcahaie.

\section{Evolution analysis of the land use and occupation in arrondissement of Arcahaie-Haiti (1987, 1997 AND 2018)}

\begin{abstract}
A B S T R A C T
Currently, the nature resources are used in an exploratory way, without the projection of the impacts that this attitude can cause, generating social and / or environmental problems, can present their effects quickly or in a large scale of time. In Haiti, it appears that their inability to face any environmental problem is directly related to anthropic activities. In this sense, the present research had as main objective to analyze the temporal evolution of the use and occupation of the land of the Arrondissement of Arcahaie, located to the West of Haiti. The Arrondissement is an administrative division of Haitian territory that decomposes several municipalities. The method used was a photointerpretation on the clipping of the Landsat 5 and Landsat 8 images, referring to the study area. Supervised classification was used for the mapping. The classes of use and occupation defined were pasture, vegetation cover, exposed soil, cultivated area, urban area, natural forest. The most significant results show changes in the dynamics of use and occupation in the Arrondissement of Arcahaie during the last 31 years and, consequently, can cause damage, often irreversible to the environment and compromise the quality of life of the population.
\end{abstract}

Key words: Environmental impacts, Natural resources, Arrondissement of Arcahaie

\section{Introdução}

Os estudos sobre impactos ambientais considerados como alterações no ambiente causadas pelo desenvolvimento das atividades humanas no espaço geográfico são de suma importância para a proteção dos recursos naturais. Estes impactos podem ser positivos, quando resultam em melhorias para o ambiente, ou negativos, quando essas alterações causam problemas nos ecossistemas terrestre e marinho. 
Ao discutir a relação homem-natureza, Crumley (1993) afirma que os problemas ambientais muito presentes na atualidade, como manutenção da biodiversidade, mudanças climáticas e sustentabilidade têm sua gênese no passado.

O crescimento populacional nas cidades vem aumentando as dificuldades na vida cotidiana - é válido ressaltar que o crescimento populacional não é um fator isolado no aumento das dificuldades da vida cotidiana e da demanda por recursos naturais e de infraestrutura. Também, a falta de planejamento territorial, a insuficiência/ineficiência de políticas públicas, a omissão por parte do poder público, aliado ao crescimento populacional concentrado nas cidades etc. Esse contexto pode levar ou agravar a situação de pobreza e vulnerabilidade social (PNUE, 2019).

Um dos reflexos dessa negligência é percebido facilmente entre a população, como no caso da carência do saneamento básico, o que prejudica além do próprio meio ambiente, a saúde humana com a contaminação do solo, dos corpos d'água, os alimentos e a qualidade do ar, implicando em inúmeros casos de doenças no Arrondissement de Arcahaie e de outros lugares em situação semelhante.

O Bureau des Mines et de l'Energie (Secretária de Minas e Energia) apresenta o Haiti como um país essencialmente montanhoso $(\sim 80 \%)$ com terreno muito acidentado, com a presença de 30 grandes bacias hidrográficas ou unidades hidrológicas. Mais de um terço do território está entre os 200 e os 500 metros de altitude, $40 \%$ acima dos 500 metros e $17 \%$ acima dos 800 metros, acima do nível do mar. Por outro lado, mais da metade das terras têm declives superiores a $40 \%$ e um quarto do território é formado por planícies (BME, 2015).

Para o climate-data.org (2018) o clima no Haiti é tropical e a temperatura média anual é de ordem $25.8{ }^{\circ} \mathrm{C}$, a pluviosidade é de $1341 \mathrm{~mm}$ de média anual. De acordo com a atual a subdivisão, o território haitiano é dividido administrativamente em dez (10) departamentos que são: le Nordoueste, le nord, Nord-Est, l'Artibonite, le Centre, l'ouest, les Nippes, la Grand Anse, le Sul e le Sul Est. Estes departamentos estão divididos em 140 comunas subdivididas, por sua vez, em 571 secções comunais (Cnra, 2002).

Do ponto de vista geográfico, o departamento é considerado como a maior divisão territorial que agrupa os Arrondissements e os municípios. O Arrondissement que é obviamente uma das divisões do departamento que inclui vários municípios. Enquanto o município é composto pela cidade, os bairros e as seções rurais que são subdivisões territoriais básicas. Deve-se notar que a seção rural se tornou uma entidade territorial do código rural de François, Duvalier (Papa Doc) e é dividido em Habitação, a qual se subdivide em lakou (localidade). A consideração da Seção Comunitária como uma entidade foi iniciada com a Constituição de 1950 (Cnra, 2002).

O Arrondissement de Arcahaie é conhecido também por sua antiga prosperidade com a disponibilidade, por exemplo, de minas (marga, argila cerâmica). Atualmente, encontram-se várias empresas importantes como: le Cimenterie d'Haiti (Cabaret), la Minoterie d'Haiti tornou-se "Les Moulins d'Haiti (Cabaret), l'usine de vetiver Jean Audain (Arcahaie). Apesar da urbanização desordenada durante os quase 40 anos, a localidade faz parte dos lugares turísticos mais importantes do Haiti, graças as suas bonitas praias (Le Nouvelliste, 2009).

Dentre as ações que visam solucionar os impactos ambientais, Martinez (2006), apresenta o planejamento físico integrado como um conjunto de decisões sobre o uso da terra, tomadas à luz das necessidades sociais, econômicas, políticas e ambientais, atividades e preferências de um determinado grupo humano. Esse planejamento abrange desde a organização da economia nacional, até a renovação de um bairro, através da gestão do ordenamento territorial, desenvolvimento regional, planejamento urbano, proteção de espécies ecológicas sensíveis, políticas de turismo, aplicação de equipamentos coletivos ou estudos de impacto.

Neste contexto, destaca-se a importância dos estudos das análises multitemporais relacionados ao uso e cobertura da terra. Atualmente existe diversas contribuições e técnicas referentes a uma variedade de modelos e técnicas de aplicação das Geotecnologias no mapeamento da evolução e transformações da paisagem (Souza et al., 2020). Autores como Fisch et al., (2019); Souza et al., (2019); Alexandre et al.; (2019), Neves et al.; (2019); Bonilha e Sato (2020); Cristo e Noleto (2020); Silva et al., (2020); Furtado et al.; (2020); Paixão et al., (2020); Pessi et al., (2018); Leite et al., (2018); Pôssa et al., (2018); Santos e Lima (2018); Silva e Lima (2018); Silva (2018); Vieira et al., (2018); Erthal et al., (2018) e Trevisan et al., (2018) utilizaram em seus trabalhos análises multitemporais para avaliar e analisar as transformações e dinâmicas acerca do uso e cobertura da terra, uso e ocupação, uso do solo, fragmentação da paisagem, utilizando imagens de satélite do sensor Landsat 5, Landsat 7, Landsat 8, plataforma Google Earth, imagens Modis, imagens SAR-PALSAR, Sentinel, dentre outros. 
Lopes e Grigio (2019) em sua pesquisa no municipio de Tibau, no Estado do Rio Grande do Norte, realizaram uma análise multitemporal, utilizando imagens de satélite dos anos de 1999 (Landsat 5), 2006 (Landsat 5) e 2016 (Landsat 8), tiveram como finalidade avaliar as alterações ocorridas na paisagem. Aplicaram a metodologia de Grigio, Amaro e Diodato (2009) para cruzamento dos mapas de uso e ocupação desses anos com a finalidade de se entender as transformações ocorridas na paisagem.

Souza et al., (2020) em seu trabalho "Mapeamento multitemporal e análise das formas de uso e ocupação do solo nos municípios de Baianópolis e Cristópolis, Bahia, Brasil", os autores tiveram como objetivo avaliar o uso e ocupação do solo do Cerrado de dois municípios do Oeste da Bahia, Cristópolis e Baianópolis, região onde predomina a atividade de agricultura. Para alcançar este objetivo, os pesquisadores utilizaram imagens do sensor Landsat 5, sensor TM (ThematicMapper) e Landsat 8, dos anos de 1989, 1994, 1999, 2004, 2009 , 2014 e 2019. Essas imagens foram tratadas e, em seguida, submetidas à classificação supervisionada, onde foram identificadas seis classes de uso e ocupação do solo: área urbana, agricultura, queimadas, solo exposto, vegetação rasteira e vegetação densa. Essa classificação, demonstra que houve crescimento da agricultura ao longo dos últimos 30 anos, acompanhado pelo aumento das queimadas e de solo exposto, evidenciando que o crescimento econômico proporcionado pela atividade agro veio acompanhado de considerável degradação ambiental, atingindo a fitofisionomia do Cerrado nativo dos municípios analisados, que são as vegetações rasteiras e densas.

Araujo et al., (2020) em seus estudos buscaram mapear as formas de uso e ocupação do Corredor Ecológico do Rio Pacoti (Ceará) realizando uma análise multitemporal com o objetivo de verificar a evolução de uso e ocupação e se ele desempenha seu papel de conectividade. Utilizaram a classificação de imagens satélite do programa Landsat, 5 e 8, e levantamentos de campo.

Os mapas da cobertura do solo foram obtidos por meio da classificação de imagens de satélite do programa Landsat, operações 5 e 8, nos respectivos sensores Thematic Mapper (TM) e Operational Land Imager (OLI), e levantamentos de campo. Os resultados evidenciaram que houve uma redução significativa da classe solo exposto de 1985 ao ano 2000 e aumento da vegetação entre os anos de 1985 a
2015. Os autores constataram nos resultados que a manutenção do corredor ecológico tem sido eficaz nos anos estudados.

Deste modo, o objetivo deste trabalho é analisar a evolução do uso e ocupação das terras no Arrondissement de Arcahaie-Haiti (1987, 1997 e 2018). Visando responder o seguinte questionamento: Os municípios do Arrondissement de Arcahaie tem capacidade de enfrentar qualquer problema ambiental, de acordo com o seus usos e ocupação? O presente estudo parte do pressuposto de que a incapacidade dos municípios do Arrondissement de Arcahaie de enfrentar qualquer problema de caráter ambiental tem a sua gênese no uso e ocupação inapropriados da terra. Baseandose na importância do ecossistema para a vida humana, o presente estudo buscou realizar um diagnóstico e mapeamento multitemporal de uso e cobertura da terra.

\section{Material e métodos}

\section{Área de estudo}

O Arrondissement de Arcahaie é um distrito do Haiti, subdivisão do departamento do Oeste. Essa zona também é subdividida em dois municípios: $\mathrm{O}$ município de Arcahaie e o município de Cabaret (Figura 1). O município de Arcahaie é famoso por sediar em 18 de maio de

1803 o Congresso de Arcahaie que deu origem à criação da bandeira nacional haitiana pelo pai da pátria, Jean-Jacques Dessalines, rasgando o branco da bandeira francesa e costurando o azul e vermelho por Catherine Flon para simbolizar a união de negros e mulatos. É uma grande região agrícola, onde predomina o cultivo de cana-deaçúcar, arroz, tabaco, café e limão. Outras práticas de culturas alimentares como mandioca, milho, feijão, ervilhas, tomate e berinjela são presentes nessa região (IHSI, 2015).

O município de Arcahaie também é conhecido por estar entre os maiores produtores de bananas do Haiti, suas praias de areia branca, locais históricos e turísticos. O centro da cidade chamado de planície de Arcahaie é uma planície costeira. Essa planície se estende no departamento do Ocidente e ao redor da principal cidade do distrito de Arcahaie (IHSI, 2015). 


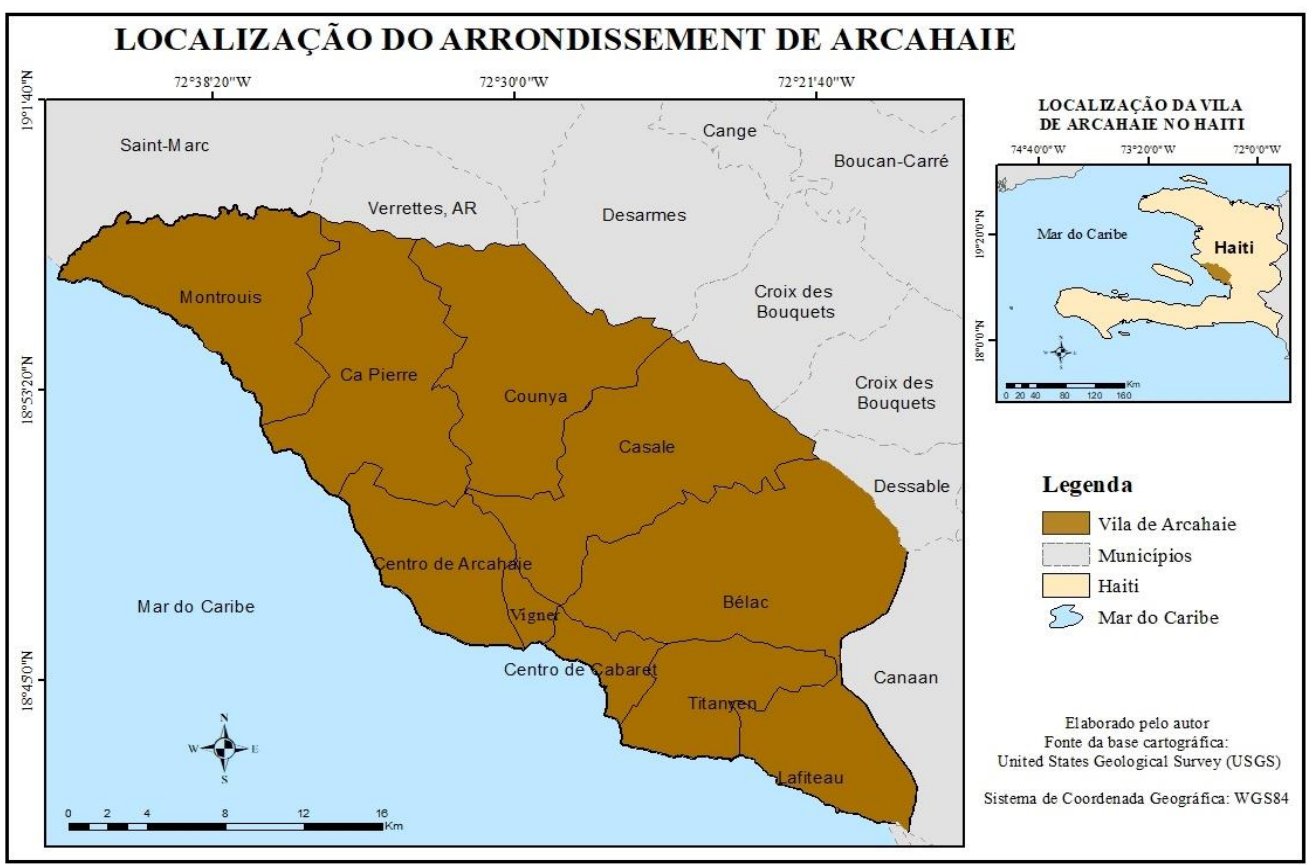

Figura 1. Mapa da Localização do Arrondissement de Arcahaie-Haiti.

De acordo com o censo de 2015, do Instituto Haitiano de Estatística e de Informática, o município de Arcahaie tem uma população de 130.306 habitantes e uma área de 408,7 km². De forma administrativa, o município é subdividido em oito seções comunais: $1^{\text {ere }}$ Section Boucassin; $2^{\mathrm{e}}$ Section Fonds Baptiste; $3^{\mathrm{e}}$ Section des Vases, $4^{\mathrm{e}}$
Section Montruis; $5^{\mathrm{e}}$ Section Délices; $6^{\mathrm{e}}$ Section Matheux (parte rural). La ville de l'Arcahaie; Quartier de Saintard (parte urbana). O Arrondissement de Arcahaie (os municípios de Arcahaie e Cabaret) tem uma população de 198.551 habitantes (Figura 2).

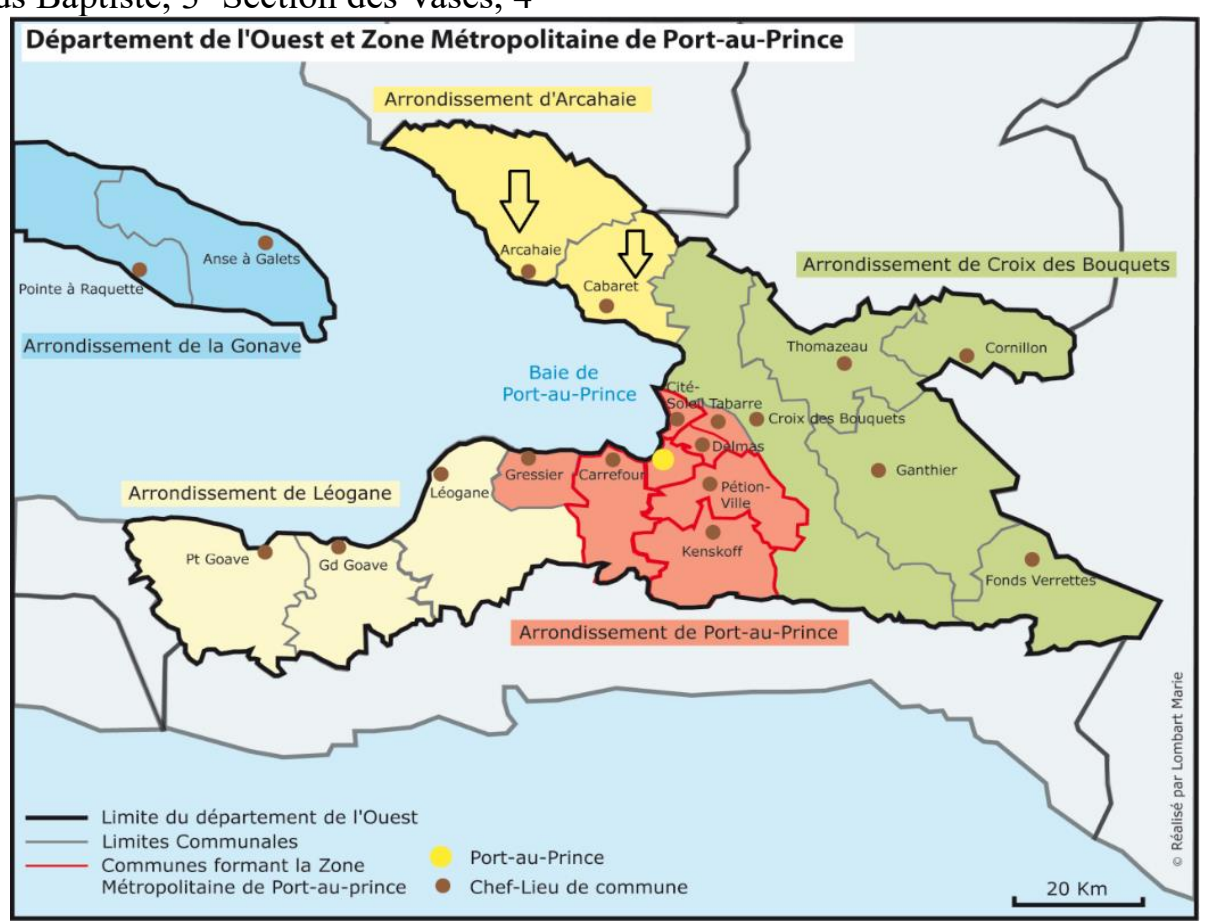

Figura 2. Departamento Oeste e a Região Metropolitana de Porto Príncipe Fonte: IHSI, 2015

Por outro lado, o município de Cabaret foi construído pelo Estado haitiano na década de 60, era uma cidade moderna e bem elaborada, respeitando os padrões urbanos. Mesmo em períodos chuvosos, poderia normalmente circular nas ruas. No entanto, a partir dos anos 80, a 
instabilidade política teve um impacto considerável no município de Cabaret, particularmente o centro velho passa a ser significativamente alterado por um crescimento urbano desordenado. Cabaret foi considerado como município em 21 de junho de 1933, sob o governo do presidente Stenio Vincent, e é a porta de entrada para "les cotes des Arcadins" um importante centro turístico. O município possui uma área de 204,89 $\mathrm{km}^{2}$ e está dividido em 4 seções comunais: 1ere section Boucassin, 2eme section Boucassin, 3eme section source Matelas, 4eme section Fonds des Blancs (IHSI, 2015; Charles, 2017).

De acordo com o censo de 2015 do IHSI, o município de Cabaret tem uma população de 68.245 habitantes, o que dá uma densidade de 346 habitantes por quilômetro quadrado, distribuídos tanto nas zonas rurais como nas zonas urbanas. Quase $78 \%$ dessa população vive em áreas rurais. Cerca da metade $(51,7 \%)$ da população do município são mulheres. A escassez de homens é muito mais pronunciada nas áreas urbanas (86 “Aw", com $26,6^{\circ} \mathrm{C}$ de temperatura média e $964 \mathrm{~mm}$ de média anual de pluviosidade. Para Jeune (2015), a região apresenta dois tipos de clima devido à variação da altitude. O tipo tropical "Aw" caracteriza as planícies e colinas que têm uma baixa variação de temperatura durante ano; enquanto nas regiões mais altas encontra-se o tipo "Cwb", ou seja, clima tropical de altitude com inverno seco e verão quente.

\section{Procedimentos Metodológicos}

A primeira etapa compreendeu ao levantamento de informações, tais como, análise bibliográfica e cartográfica da área de estudo, a fim de subsidiar a dinâmica de uso e ocupação da terra. Foram realizados trabalhos de levantamento bibliográfico, composto por revisão e análise de artigos nacionais e internacionais, teses e dissertações que tratam do tema em discussão. Foram analisados os trabalhos, artigos e teses realizadas na área de estudo que fizessem referência à caracterização antrópica (economia e história) na região do Caribe e mais especificamente no departamento Oeste do Haiti.

Para a realização do mapeamento de uso e ocupação da terra optou-se por representar documentos em escalas temporais distintas representando a dinâmica do uso e ocupação da terra ao longo dos últimos 31 anos. Para os mapeamentos foram utilizadas imagens de satélite do Landsat 5; e Landsat 8 dos anos de 1987, 1997 e 2018 com base na interpretação das imagens de satélite, as classes de homens para cada 100 mulheres) do que nas áreas rurais (95 homens para cada 100 mulheres). A distribuição da população é representada da seguinte forma: $68 \%$ são pessoas com idades entre 15-64 anos, e 32\% são pessoas acima de 65 anos (IHSI, 2015).

De acordo com Instituto Haitiano de Estatístico e de informático (IHSI, 2015), o Arrondissement de Arcahaie está localizado no departamento Oeste da República do Haiti, com uma população total de 198.551 habitantes, para uma área de $613,59 \mathrm{~km}^{2}$. De forma geográfica esta região é delimitada a norte pelo município de Saint Marc, a sul pelo mar do Caribe, a leste pelos municípios do Croix-des-Bouquets e Verettes, e a oeste pelo mar do Caribe.

O Arrondissement de Arcahaie, assim como o departamento, possui clima tropical. No inverno existe pouca pluviosidade em relação ao período do verão. Segundo a classificação de Köppen e Geiger o clima é classificado como

uso e ocupação das terras, foram definidas a partir da adaptação do Manual Técnico do IBGE (2013), a seguir: área urbana, área rural, área cultivada, cobertura vegetal, vegetação rasteira e solo exposto.

Para a organização da base de dados, efetuou-se o download das imagens Landsat 5 e Landsat 8 no site do United States Geological Survey (USGS, 2018), e de fotografias aéreas disponibilizadas pela Bureau des Mines de l'Énergie (Secretária de Minas e de Energia, em português) (1987). A realização do mapa de uso e ocupação da terra, teve como objetivo, acompanhar a evolução através das imagens de satélite, permitindo o processo técnico de análise e interpretação específica na área de estudo. Para a realização do mapeamento de uso e ocupação da terra, optou-se por representar em uma escala temporal, representando a dinâmica do uso e ocupação da terra durante os últimos 31 anos (Quadro $1)$.

O procedimento adotado para o mapeamento foi desenvolvido no software eCognition, através da classificação supervisionada, sendo esta segmentação orientada ao objeto. Após a segmentação foi realizada uma avaliação visual dos arquivos gerados, para avaliar o desempenho. Para isso, as imagens rasters resultantes da segmentação foram transformados em arquivos vetores, e em seguida importados para o ArcGIS 10.4. As edições e correções foram realizadas todas manualmente, através da interpretação e reconhecimento visual das imagens de satélite dos respectivos anos. 
Quadro 1: Informações das imagens de satélite utilizadas no mapeamento multitemporal.

\begin{tabular}{|c|c|c|}
\hline Ano & Pixel & Satélite \\
\hline 1987 & $30 \mathrm{~m}$ & Landsat 5 \\
\hline 1997 & $30 \mathrm{~m}$ & Landsat 5 \\
\hline 2018 & $30 \mathrm{~m}$ & Landsat 8 \\
\hline
\end{tabular}

Fonte: $\mathrm{O}$ autor.

Para a confecção dos mapas foi necessária a realização de atividades de campo, junto com informações levantadas para de uso e ocupação do solo dos anos de 1987, 1997 e 2018. O trabalho de campo teve a duração de três (3) meses, de 8 de maio de 2018 até 6 de agosto de 2018, para a coleta de dados primários no Arrondissement de Arcahaie (Haiti). Outra informação importante na elaboração deste documento foram os dados disponibilizados pelo Instituto Haitiano de Estatística e de Informática

\section{Resultados e discussão}

Atualmente, em Arcahaie, mais de $80 \%$ da população vive da agricultura. A densidade populacional é alta, da ordem de 280 habitantes $/ \mathrm{km}^{2}$, considerada como uma forte pressão. A maioria das fazendas são pequenas fazendas familiares: mais de $70 \%$ delas têm menos de 1,3 ha e $55 \%$ menos de 0,6 ha. Fazendas de empregadores, herdeiras de uma grande propriedade que foi dividida por gerações, são em menor número e cultivam áreas entre 1 e 5 ha. Finalmente, existem poucas grandes unidades de produção (5 a 25 ha): estas explorações capitalistas foram mantidas ao longo da história de Arcahaie e agora são exploradas diretamente por um gerente (IHSI, 2015).

Durante o período colonial (1697-1804), os franceses estabeleceram em Arcahaie grandes fluxos de escravos nas plantações para a produção de açúcar. Por volta do século XVII as terras férteis da planície aluvial foram desenvolvidas para irrigação e Arcahaie tornou-se uma região de produção de cana-de-açúcar importante (SaintMéry, 1797, Charles, 2017). Após a Independência, em 1804, uma estrutura agrária baseada na coexistência de grandes propriedades e propriedades familiares sucedeu colonatos coloniais.
(IHSI), através dos censos de 2015, como também informações demográficas e econômicas sobre o Arrondissement de Arcahaie.

Os documentos cartográficos de uso e ocupação da terra elaborados dizem respeito aos anos de 1987,1997 e 2018. Os mapeamentos são resultantes da interpretação visual das imagens Landsat 5 e Landsat 8.

Grandes latifundiários, muitas vezes moradores das cidades próximas ao poder, se beneficiavam da terra doada pelo estado para continuar produzindo açúcar. Esta política fundiária visava a reconstituição de áreas agroexportadoras cuja produção estava sujeita a altos impostos de exportação; os últimos destinavam-se a fornecer o orçamento da nova nação à qual a França pagava caro pelo preço da Independência.

No Brasil, Miranda et al., (2019) discute a problemática ambiental decorrente dos impactos da produção de cana-de-açúcar sobre a sociedade e o meio ambiente. No Haiti não é diferente, as áreas, que haviam sido montadas, foram exploradas parcialmente pela empresa, contrato pelo qual o arrendatário se comprometia a respeitar as exigências culturais do proprietário: produtos alimentícios em uma parte da fazenda e cana-deaçúcar nas demais. Metade da lavoura de alimentos foi para o proprietário, assim como toda a lavoura de cana (Deverre, 1987). Até a década de 80, o Arrondissement de Arcahaie era um distrito moderno, respeitando as normas urbanas, de acordo com a constituição de 1987. A Figura 3 mostra o uso e ocupação da terra desta região para o ano de 1987. 


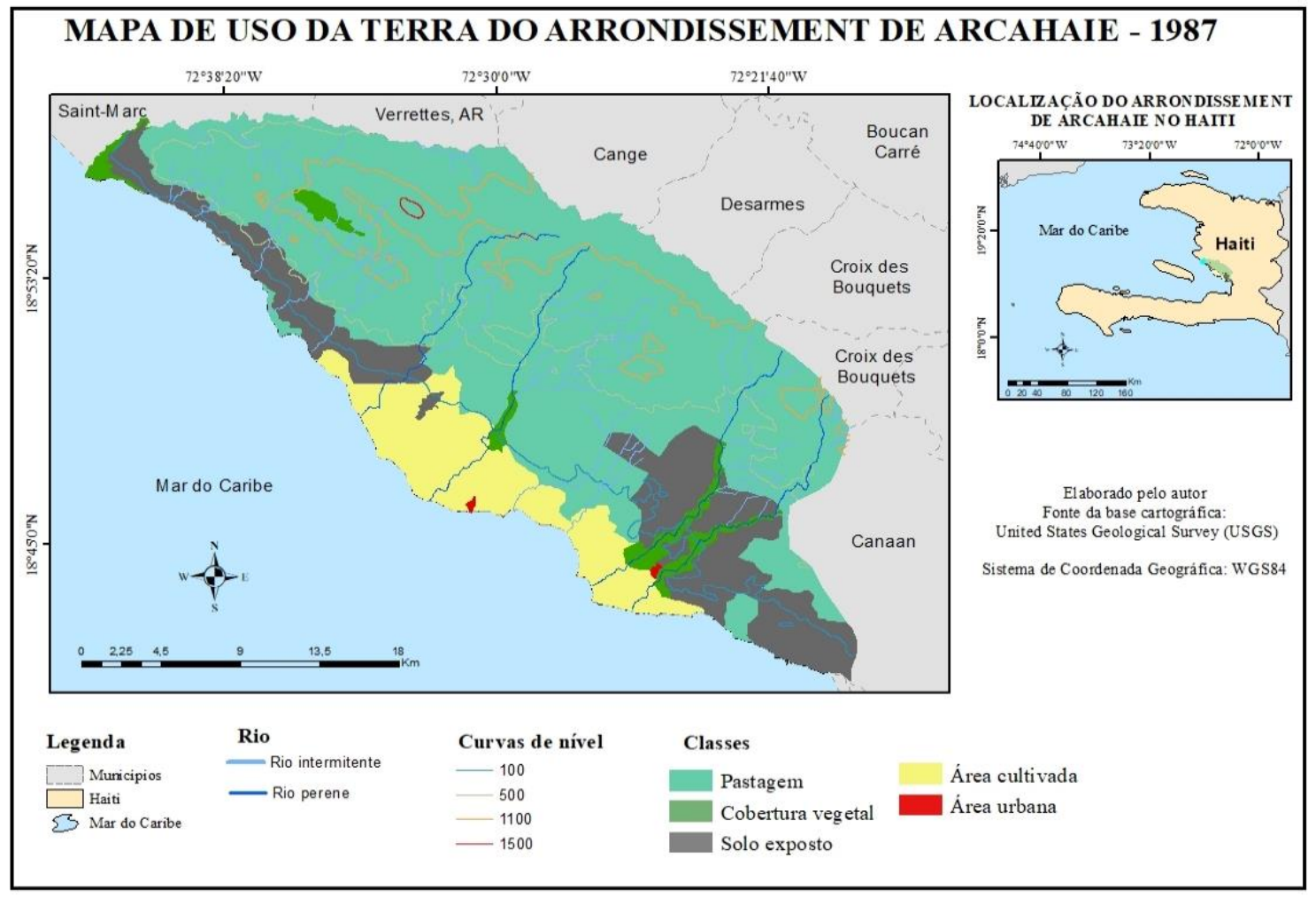

Figura 3. Mapa de uso e ocupação das terras na região de Arrondissement de Arcahaie-Haiti-1987

Observou-se no mapa de uso da terra de 1987, que há uma predominância de pastagem. É importante também notar a presença das matas naturais na borda dos rios. É uma prova que na década de 80 o êxodo rural no Haiti, assim como na área de estudo, não era tão severo em comparação a atualidade.

Durante o início da década de 1980,70\% da área total do Arrondissement de Arcahaie era coberta por vegetação rasteira. As áreas urbanas representam somente $2 \%$. Na discussão do geógrafo Michel retomado por Roc (2008), o autor afirma que antes da ocupação Americana no Haiti (1915- 1934) a cobertura florestal do território haitiano representava $60 \%$, já depois da ocupação, em 1945, a cobertura florestal passou de $60 \%$ a $21 \%$, e em 1954 houve declínio para um percentual em torno de 9\%. Existi uma certa semelhança entre a cobertura vegetal brasileira e a cobertura da vegetação haitiana, os problemas ambientais também são semelhantes, ou seja, a devastação da vegetação para a exploração econômica. No Brasil, Souza et al., (2020) discute o desenvolvimento econômico proporcionado a partir das atividades economicas, com destaque para o agro no Oeste Baiano, este desenvolvimento veio acompanhado da degradação ambiental, atingindo as vegetações rasteiras e densas do Cerrado.
O êxodo rural se intensificou durante os trinta anos de ditadura do presidente Jean-Claude Duvalier (papa Doc) que trouxe milhões de habitantes das áreas rurais para residir em Porto Príncipe, cujo objetivo era fortalecer o seu poder, ou seja, o presidente pagou estes para protestar nas ruas da capital do país a favor do seu poder. Devido às boas condições de saneamento básico na capital haitiana naquela época, os migrantes não regressaram para as áreas rurais, além disso, o governo não financiou o retorno destes à sua terra natal. O conjunto de habitantes que resolveu não retornar migrou para a região metropolitana de Porto Príncipe (Figura 3). O Arrondissement de Arcahaie devido a sua proximidade da capital Haitiana recebeu parte significativa destes moradores (ROC, 2008).

De forma geral, o fenômeno do êxodo rural proliferou no Haiti após a queda do Duvalier (Baby Doc) em 1987, onde a população escapa cada vez mais a certas restrições que consiste em deixar o campo para se instalar nas cidades, a fim de encontrar uma vida melhor. De fato, esse fenômeno está em grande parte na irresponsabilidade do estado haitiano, no sentido de que, geralmente, as pessoas que vivem no campo não se beneficiam realmente da presença das autoridades que administram as localidades. 
O processo histórico relatado pode ser uma das explicações para entender a degradação ambiental ao redor de Porto Príncipe. A população local suprimiu a vegetação natural para a construção habitacional sem recorrer às normas legais. Este fato também contribuiu para propulsionar a formação das primeiras favelas na região metropolitana de Porto Príncipe, implicando em cenários como desmatamento, perda de solo por erosão, insalubridade, perda de biodiversidade, exploração de forma desordenada nas áreas de mineração, degradação do ecossistema marinho, urbanização, pressão demográfica e pobreza (ROC, 2008). Observe na Figura 4, uma redução significativa em porcentagem das áreas ocupadas por vegetações rasteiras, e, por outro lado, uma expansão de forma rápida das áreas sobrecarregadas por solos expostos.

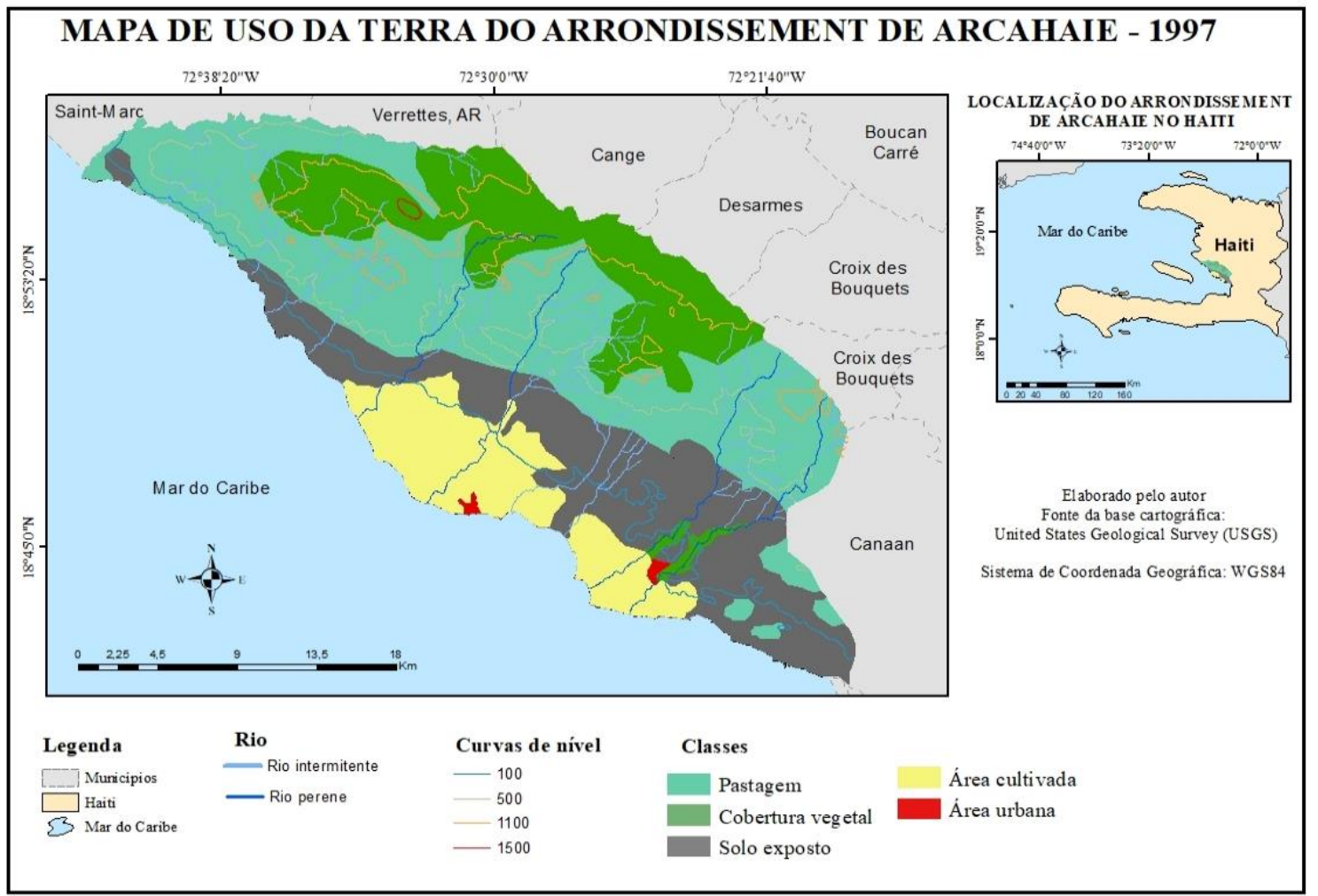

Figura 4. Mapa de uso e ocupação das terras na região de Arrondissement de Arcahaie-Haiti-1997.

Uma das consequências imediatas do êxodo rural no Arrondissement de Arcahaie é o fenômeno de desmatamento. Este cenário é presente em todo território haitiano. A título de exemplo, prospere e Martin (2011), comparam a situação ambiental dos dois países (Haiti e República Dominicana) que dividem a Ilha Espanhola, constatando que ambos os países perderam florestas, mas o maior impacto é registrado no Haiti. O autor afirma que atualmente $28 \%$ da República Dominicana ainda são cobertas de florestas, enquanto o Haiti tem $1 \%$ de cobertura florestal. Esse é um dos principais problemas enfrentados em todos os paises, a redução da cobertura vegetal. No Brasil, autores como Pessi et al., (2018); Silva e Lima (2018) constataram em seus trabalhos a redução ou fragmentação da cobertura vegetal, esse é o principal impacto ambiental que ocorre em escala global.

De acordo com estes autores, a diferença florestal e ambiental entre esses dois países reflete em vários aspectos, tais como na economia, agricultura e no social. Reconhecidamente, a República Dominicana e o Haiti são países pobres, que passaram por complexas problemáticas, como a maioria dos países tropicais, no seu processo de colonização europeia, o que originou problemas como corrupção e deficiências no ramo da saúde, educação e no setor agrícola.

A agricultura, em particular, é considerada uma das principais atividades econômicas no Arrondissement de Arcahaie, visto que a metade da população deste país reside em áreas rurais e obtém a sua renda desta atividade. Desde o final do século XVIII, devido à alta produção de banana, mandioca, feijão e outros produtos agrícolas, o Arrondissement de Arcahaie tornou-se gradualmente um dos principais celeiros de alimentos de Porto Príncipe (Théodat, 2003). Contudo, esta atividade pode gerar impactos negativos no cenário ambiental, quando praticada de maneira inadequada e com o uso irracional dos 
recursos naturais. Aqui no Brasil, destaca-se a produção agroindustrial, principalmente com o cultivo da soja. Silva et al.; (2020) destaca que esse tipo de cultivo vem acompanhado pelo aumento das queimadas e de solo exposto.

Consumidas em diferentes formas, as bananas ocupam um lugar importante na alimentação dos haitianos. No Departamento do oeste, por exemplo, a banana-da-terra continua sendo o principal alimento da população. Neste produto também está a economia de certas regiões do departamento do oeste, incluindo as comunas de Arcahaie e Cabaret. No entanto, essa commodity está se tornando cada vez mais rara no mercado local; uma raridade devido ao declínio na produção causada principalmente pelo fungo conhecido como Sigatoka negra.
É importante salientar que no território haitiano, a agricultura não possui formas específicas de uso costeiro, mas diferentes dinâmicas marcam a paisagem e contrastam as regiões costeiras do Canal Sul e do Canal SaintMarc (norte de Arcahaie). Com efeito, ao longo da costa des Arcadins, a agricultura é inexistente, devido à posição de abrigo imposta pela cadeia de Matheux e pela forte erosão do solo. Estas áreas costeiras, assim como outras costas do Caribe, são frágeis e, desde o final do década de 1980, sofreram transformações que estão se acelerando. No Arrondissement de Arcahaie, percebe-se uma expansão de forma rápida das áreas rurais após o terremoto de 2010 que abalou a capital haitiana. A Figura 5, ilustra a forma rápida de uso e ocupação desordenada no Arrondissement de Arcahaie durante o ano de 2018.

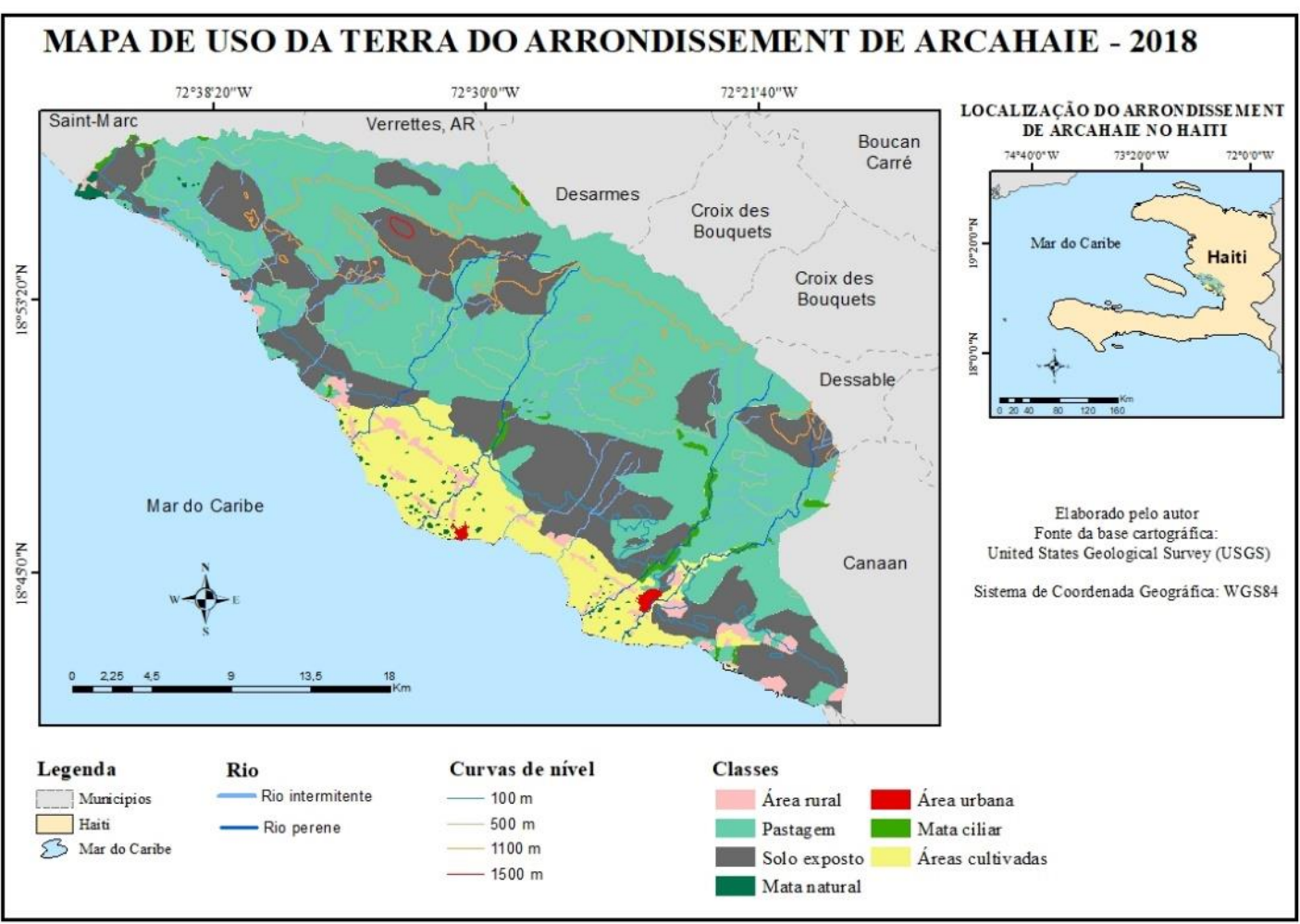

Figura 5. Mapa de uso e ocupação das terras na região de Arrondissement de Arcahaie-Haiti-2018.

A figura 5, mostra o surgimento de várias áreas ocupadas após o terremoto, bem como o aumento de áreas com solos expostos. Uma das explicações para este fenômeno tem relação com a migração (em decorrência do terremoto) de parte da população de Porto Príncipe para o Arrondissement de Arcahaie, em busca de melhor qualidade de vida e de infraestruturas básicas, que resultou numa sistemática supressão da vegetação rasteira para a construção de novas casas. Por outro lado, observa-se que algumas áreas deixaram de ser cultiváveis para a construção de habitações.

Esta forma de ocupação faz surgir outras cidades na área metropolitana de Porto Príncipe. Para exemplificar, Canaan é uma das muitas áreas em rápida expansão, que abriga entre $280.000 \mathrm{e}$ 320.000 pessoas. A ocupação desta área começou no dia do terremoto (12 de janeiro de 2010), já que as vítimas que estavam fugindo do caos nos bairros adjacentes de Porto Príncipe, migraram das zonas rurais do Haiti em busca de melhor qualidade de 
vida. É importante ressaltar que o governo do Haiti inicialmente se recusou a reconhecer assentamentos permanentes, por exemplo o de Canaan, proibindo oficialmente a construção de estruturas permanentes ou a implementação de projetos de infraestrutura na área. Com o tempo, a propriedade de terra de fato foi aceita e os doadores têm projetos de financiamento, incluindo estradas e sistemas de água. Porto Príncipe foi a área mais afetada pelo terremoto e assistimos ao movimento contrário, ou seja, os habitantes de Porto Príncipe migraram para as áreas rurais.

O Instituto Haitiano de Estatística e de Informática (2015) estima que 600.000 pessoas deixaram a cidade logo após o terremoto que destruiu a infraestrutura econômica e habitacional da capital haitiana. Apesar dos problemas socioambientais e falta de infraestrutura básica, o Arrondissement de Arcahaie recebeu grande parte dos migrantes devido a sua proximidade com a capital haitiana; por ter sido menos atingida pelo terremoto comparado com Porto Príncipe; e, por fim, por ter o saneamento básico mais adequado quando em comparação as outras regiões da área metropolitana de Porto Príncipe. Por conta do horário em que ocorreu e dos locais que sofreram o maior impacto, o terremoto jogou por terra a esperança de vida de milhares de jovens, funcionários públicos e profissionais qualificados. Esta situação dificulta ainda mais a questão ambiental na área de estudo que já era um grande desafio para as autoridades locais.

Embora a atual oscilação climática esteja claramente pressionando as áreas costeiras do Haiti, vários fatores não relacionados ao clima aumentam a vulnerabilidade ambiental do Arrondissement de Arcahaie devido a ocupação terra de forma inadequada, o que limita sua capacidade de adaptação as possíveis mudanças climáticas. As principais ameaças imediatas aos sistemas costeiros na área de estudo são: a urbanização anárquica e desregulamentada ao longo da costa, sustentada pelo rápido crescimento populacional e pela crescente migração rural; práticas agrícolas insustentáveis, incluindo sobre pastoreio, bombeamento excessivo de aquíferos costeiros e destruição de manguezais para produção agrícola ou de carvão; e poluição de corpos de água e ecossistemas costeiros devido a falhas ou falta de recursos e sistemas de tratamento de água urbana. Essas pressões estão levando à destruição de zonas-tampão naturais, tornando o ecossistema mais vulnerável aos efeitos das mudanças climáticas e do aumento do nível do mar (Le Nouvelliste, 2019).

\section{Conclusões}

A natureza é a condição fundamental para a sobrevivência humana, desde seu estágio natural até a sua transformação (espaço geográfico) executada pela ação humana, a chamada segunda natureza. A necessidade de satisfazer os desejos do ser humano resultou numa profunda relação com o meio ambiente para a utilização dos recursos naturais disponíveis, apesar de que qualquer forma de exploração dos componentes do espaço natural cria desequilíbrio no funcionamento dos sistemas. Para isso, é fundamental operacionalizar as formas de pensar e de agir para gerar um produto científico capaz de apresentar o cenário e discutir sobre o seu funcionamento da natureza baseando-se na visão geossistêmica.

No mapa dos sistemas antrópicos, constatamos que a população local suprimiu a vegetação natural para a construção habitacional sem recorrer às normas legais estabelecidas pelo Ministério de Trabalhos Públicos Transporte e Comunicação (MTPTC, 2010). Este fato também contribuiu para propulsionar a formação de favelas ao redor do centro urbano do município de Cabaret, implicando em cenários como desflorestamento erosão de perda de solo, insalubridade urbana, perda de biodiversidade, exploração de forma desordenada nas áreas de mineração, degradação do ecossistema marinho, urbanização, pressão demográfica e pobreza.

Cerca de $80 \%$ da população do Arrondissement de Arcahaie utiliza o carvão de madeira como fonte de energia, é o que explica o elevado grau de desmatamento observado em comparação os mapas de usos e ocupações de 1987 e 2018. Nesse contexto econômico e social deprimido, com a forte demanda por carvão vegetal em todo o país para uso doméstico, o corte de árvores está se acelerando e alcançando proporções extraordinárias" - trata-se de argumentos que corroboram com os resultados, e devem ser devidamente referenciados.

Por outro lado, uma política que visa o planejamento ambiental integral pode incentivar a mudança de hábitos no uso e ocupação da terra para se adotar um estilo de vida mais sustentável e benéfico para o bom funcionamento do ecossistema do Arrondissement de Arcahaie. 


\section{Agradecimentos}

Agradecimento a Coordenação do Aperfeiçoamento de Pessoal de Nível Superior (CAPES).

\section{Referências}

Alexandre, F.S., Souza, S.O., Oliveira, G.F., Silva Neto, J.B., Gomes, D.D.M., 2019. Mapeamento da cobertura e uso da terra da bacia hidrográfica do alto curso do rio Mundaú - Pernambuco / Alagoas. Revista GeoUECE (Online), 08, n. 14, p. 190-200, jan./jun. 2019. ISSN 2317-028X.

Araújo, T. M. S, Bastos, F. H, Rabelo, F. D. B. Análise Multitemporal do Uso e Ocupação do Solo no Corredor Ecológico do Rio Pacoti (Ceará) nos anos de 1985, 2000 e 2015. Geografia (Londrina) 29. 185 - 203, julho/2020.

Araujo, J. P. R., Grigio, A. M., Pereira Neto, M. C. Análise multitemporal de uso e ocupação do solo (1977-2018) e identificação de impactos ambientais negativos no município de Assú/RN. Revista Brasileira de Geografia Física .12, (2019) 1538-1553.

Bonilha, G.O.; Sato, S.E., 2020. Análise da dinâmica temporal do uso e cobertura da terra como subsídio ao planejamento do município do Rio Grande - RS. GeoUECE (online), v. 09, n. 16, p. 165-180, 2020.

Bureau des Mines et de L'énergie (BME). 2015. Inventaire des ressources minières de la République d'Haiti - dossier promotionnel Fasciculé VI Département de 1'Ouest. Direction de la géologie et des mines. Port-au-Prince Haiti. P45.

Charles, R.A., 2017. Gestão de resíduos sólidos, o grande desafio no Município de Cabaret (Haiti). Trabalho de Conclusão de Curso Geografia. Universidade Estadual de Campinas (UNICAMP), junho de 2017.

Climate-Data. ORG, 2019. Disponível em, https://fr.climate-data.org/amerique-dunord/haiti/departement-de-l-ouest/arcahaie29873/\#climate-graph. Acessado em 12 de Julho de 2019.

Commission Nationale a la Reforme Administrative - CNRA. 2002. "Unité de de Décentralisation et des Collectivités Territoriales". Mars.

Cristo, S.S.V.; Noleto, J.P.S., 2020. Análise das Transformações Ambientais da porção central do estado do Tocantins: ênfase nos aspectos de uso e ocupação da terra no município de
Brejinho de Nazaré. GeoUECE (online), 09, 147-153.

Crumley, C.L., 1993. Historical Ecology: cultural knowledge and changing landscapes. Santa Fé: School of American Research Press.

Deverre, C. Transformation Foncières et Developpement Nacional. In, enjeux fonciers dans la Caraibes, en Amérique Centrale et à la réunion: Plantations et Paysanneries. Paris: Karthala. P 15- 37.

Erthal, D. A.; Breunig, F. M.; Balbinot, R.; Rosa, P. A.; Mello, L. F.; Dinâmica da cobertura florestal da terra indígena do Guarita, RS, Brasil. Revista Brasileira de Geografia Física 11, (2018) 2160-2172.

Fensterseifer, S. L. B.; Silva, L. R. Análise multitemporal do uso e ocupação do solo, através de geoprocessamento. Revista Liberato, Novo Hamburgo, 20, 1-112, jan./jun. 2019.

Fisch, F. Branco, J.O; Port, D. Menezes, J.T; Variação espaço-temporal (1938-2013) do uso e ocupação da terra na região do saco da fazenda, Itajaí-SC. Geosul, Florianópolis, v. 34, n. $70, \quad$ p. 430-445, jan./abr. 2019. http://dx.doi.org/10.5007/21775230.2019v34n 70p430.

Furtado, L.G. Morales G.P., Silva, D. F, Pontes, A. N., 2020. Transformações do uso e cobertura da terra na bacia hidrográfica do rio Murucupi, Barcarena, Pará Revista Brasileira de Geografia Física 13.

Instituto Brasileiro de Geografia e Estatística IBGE. 2013. Manual técnico de Uso da Terra. $3^{\text {a }}$ Ed. Rio de Janeiro.

Institut Haitien de Statistique et D'informatique IHSI. 2015. Population totale, de 18 ans et plus. Menages et densités estimés en 2015. Direction des Statistiques Démographiques et Sociales (DSDS). Mars.

Jeune, W., 2015. "Solos e ambientes no Haiti ocidental: Gênese, classificação e mapeamento". Tese apresentada à Universidade Federal de Viçosa, como parte das exigências do programa de Pós-Graduação. Minas Gerais.

Lopes, D. N. Grigio A. M. Análise Multitemporal do Uso e Ocupação dos Solos do Município de Tibau - RN ao Longo dos Anos de 1999, 2006 e 2016. Anuário do Instituto de Geociências UFRJ ISSN 0101-9759 e-ISSN 1982-3908 - 42 - 3 / 2019 p. 599-608.

Le Nouvellistre, 2019. "Les charmes discrets de l'Arcahaie". Port-au-Prince, le 14 juillet.

Le Nouvellistre, 2019. "Accompagner le changement climatique" Port-au-Prince, 25 février. 
Leite, V. A. W. Rodrigues, L. P., Leite, E. F. Dinâmica do uso e cobertura da terra no município de Miranda-MS, Pantanal Sul. Revista Brasileira de Geografia Física 11, (2018) 1458-1477.

Martínez, P. 2006. Planificación Física y Ordenación del Territorio. Editorial Dykinson S. L. Madrid, España. ISBN-84-9772-920-X, pp. 1-15. Disponivel em http://books.google.com.

Ministère Des Traveaux Publics Transports Et Communications - MTPTC. 2020. Les normes de constructions en vigueur em Haiti. Le Nouvelliste, juin 2010.

Miranda, C.G. Picoli, M. C. A., Rampazo, N. A. M., Duft, D. G., Machado, P. G., Evaristo de Jesus, K. R., Perez Filho, A. Análise do uso e expansão da cana-de-açúcar na bacia hidrográfica do rio Santo Anastácio utilizando a abordagem de "Landscape Design". Revista Brasileira de Geografia Física 12, (2019) 252267.

Neves, L.V.; Deus, L.A.B., Oscar Júnior, A. C. S.; Fernandes, M. C. 2019. Mudanças de Uso e Cobertura da Terra e Áreas Suscetíveis à Inundação - Estudo de Caso do Município de Duque de Caxias/RJ. Revista do Departamento de Geografia - Volume 37.

Pessi, D. P.; Rezende, G. B. M.; Silva, N. M. Cobertura vegetal em microbacias urbanas: análise temporal da cobertura arbórea e temperatura de rondonópolis, Mato Grosso. Revista Brasileira de Geografia Física v.12, n.01 (2019) 299-309.

Paixão, T.S, et al., 2020. Multitemporalidade do uso e cobertura da terra utilizando a plataforma Google Earth: estudo de caso do Centro Sócio Educacional Fazendinha Esperança, Marituba, Pará Revista Brasileira de Geografia Física v.13, n.06.

Programme des Nations Unies pour 1'Environnement - PNUE. 2019. "Saison cyclonique 2010: avec le soutien de ses partenaires, la DPC prépare les brigadiers (ères) volontaires". Août.

Prospere, L., Martin, G. A., 2011. "A questão ambiental no?do Haiti: Um desafio na reconstrução do país". Revista Electrônica em Gestão, Educação e Tecnologia Ambiental. REGET-CT/UFSM, (3), 345-351.

Rezende, F. S., Carriello, F., Rodriguez, D. A., Neves, O. M. S. Spatial and Temporal Changes in the Land Use and Cover of the Paraíba Valley in São Paulo, Brazil: Development of Future
Scenarios. Revista Brasileira de Geografia Física 11. (2018) 1732-1747.

Roc, N., 2008. "Haiti-Environnement: de la Perle des Antilles à la desolation". FRIDE, september.

Rodriguez, J.M.M.; Silva, E. D.; Cavalcanti, A. P. B., 2013. Geoecologia da paisagem: uma visão geossistêmica da análise ambiental. Fortaleza: EDUFC.

Saint-Méry, M., 1797. Description topographique, physique, civile, politique et historique de la Partie française de l'Isle Saint-Domingue. Philadelphie, 1797).

Silva, T.C.C.; Varela, A. W. P.; Rosa, A. G., 2020. Mapeamento do uso e cobertura da terra e Savi na Apa Metropolitana de Belém. Journal of Applied Hydro-Environment and Climate, 2, 18-31, 2020 Jornal Aplicado em HidroAmbiente e Clima, .2, 18-31. https://jahec.ufra.edu.br/index.php?journal=JA HEC.

Souza, J.A.; Carneiro, C.S.; Soares, L.P.; Cunha, F. S. S., 2019. O uso de imagens SRTM e ASTER GDEM para análise de parâmetros geomorfológicos da subbacia hidrográfica do Rio Jacurutu, Santa Quitéria - CE. Revista GeoUECE (Online), 08, 363-372, jan./jun. ISSN 2317-028X.

Souza, S.S.G, et al., 2020. Análise da dinâmica do uso e cobertura da terra do Município de Moju-PA, utilizando Google Earth Engine. Revista Brasileira de Geografia Física v.13, n.05.

Silva, T. C. L. Transformações multi-temporais do uso e coberturas das terras no bairro de Cruz das Almas, litoral norte de Maceió, Alagoas, Nordeste do Brasil. Revista Brasileira de Geografia Física 12, (2019) 310-325.

Silva, S. C. S.; Lima, A. M. M. Análise do uso e ocupação da terra e sua influência na subbacia do Ji-Paraná. Revista Brasileira de Geografia Física 12, (2019) 201-212.

Souza, R. B. B.; Feitosa Júnior, F. R.; Almeida Neto, P. P.; Brandão, P. R. B. Mapeamento multitemporal e análise das formas de uso e ocupação do solo nos municípios de Baianópolis e Cristópolis, Bahia, Brasil. Revista Ibero Americana de Ciências Ambientais, v.11, n.6, p.451-471, 2020.

Theodat, J.M., 2003. Haiti/ République Dominicaine: une île pour deux $1804-1916$. Paris: Karthala.

Trevisan, D.P.; Melo, B. M.; Melo, R. M.; Moschini, L.E. Análise das mudanças do uso e cobertura da terra entre 1988 e 2017 no 
município de Ibaté-SP. Revista Brasileira de Geografia Física v.11, n. 07 (2018) 22162228.

USGS-United States Geological Survey., 2018. Acessado em junho de 2018.
Vieira, C.H.N.; Mattos, L.M.; Malaquias, J.V.; Aquino, F.G.; Martins, P.T.A. Spatial and temporal land use and land cover of the Upper Jardim River Basin, Distrito Federal, Brazil. Revista Brasileira de Geografia Física v.11, n.01 (2018) 085-098.

Charles., R., Oliveira., R., C., Souza., I., S. 